\title{
Studying the Nature Relationships between Climatic Factors and Cotton Production by Different Statistical Methods
}

\author{
Zakaria M Sawan* \\ Cotton Research Institute, Ministry of Agriculture \& Land Reclamation, Egypt
}

Submission: May 08, 2017; Published: July 26, 2017

*Corresponding author: Zakaria M Sawan, Cotton Research Institute, Agricultural Research Center, Ministry of Agriculture \& Land Reclamation, 9 Gamaa Street, 12619, Giza, Egypt, Email: zmsawan@hotmail.com

Abstract

Cotton yield is a function of growth rates, flower production rates, and flower and boll retention during the fruiting period. Information on the relationship between climatic factors and the cotton plant's ability to produce and sustain flower buds, flowers, and bolls will allow one to model plant responses to conditions that frequently occur in the field and to predict developmental rate or the formation of these organs. Understanding the impacts of climatic factors on cotton production may help physiologists to determine the control mechanisms of boll retention in cotton. However, weather affects crop growth interactively, sometimes resulting in unexpected responses to prevailing conditions. The balance between vegetative and reproductive development can be influenced by soil fertility, soil moisture, cloudy weather, spacing and perhaps other factors such as temperature and relative humidity. The early prediction of possible adverse effects of climatic factors might modify their effect on production of cotton.

\section{Introduction}

This study investigates the statistical relationship between various climatic factors and overall flower and boll production. Also, the relationship between climatic factors and production of flowers and bolls obtained during the development periods of the flowering and boll stage. Further, predicting effects of climatic factors during different convenient intervals (in days) on cotton flower and boll production compared with daily observations. Furthermore, collects information about the nature of the relationship between various climatic factors and cotton boll development and the 15-day period both prior to and after initiation of individual boll. And, provide information on the effect of various climatic factors and soil moisture status during the development stage on flower and boll production in cotton. Evaporation, sunshine duration, relative humidity, surface soil temperature at $1800 \mathrm{~h}$, and maximum air temperature, are the important climatic factors that significantly affect flower and boll production. The five-day interval was found to be more adequately and sensibly related to yield parameters. Evaporation; minimum humidity and sunshine duration were the most effective climatic factors during preceding and succeeding periods on boll production and retention. There was a negative correlation between flower and boll production and either evaporation or sunshine duration, while that correlation with minimum relative humidity was positive [1-3].

\section{Conclusion}

Evaporation, sunshine duration, relative humidity, surface soil temperature at $1800 \mathrm{~h}$, and maximum temperature, were the most significant climatic factors affecting flower and boll production of Egyptian cotton. Also, it could be concluded that the fourth quarter period of the production stage is the most appropriate and usable production time to collect data for determining efficient prediction equations for cotton flower and boll production in Egypt, and making valuable recommendations. Further, it could be concluded that during the 15-day periods both prior to and after initiation of individual bolls, evaporation, minimum relative humidity and sunshine duration, were the most significant climatic factors affecting cotton flower and boll production and retention in Egyptian cotton. The negative correlation between each of evaporation and sunshine duration with flower and boll formation along with the positive correlation between minimum relative humidity value and flower and boll production, indicate that low evaporation rate, short period of sunshine duration and high value of minimum humidity would enhance flower and boll formation. The 5-day interval was found to give adequate and sensible relationships between climatic factors and cotton production growth under Egyptian conditions when compared with other intervals and daily observations. It may be concluded that the 5-day accumulation of climatic data 
during the production stage, in the absence of sharp fluctuations in these factors, could be satisfactorily used to forecast adverse effects on cotton production and the application of appropriate production practices circumvent possible production shortage.

Finally, the early prediction of possible adverse effects of climatic factors might modify their effect on production of Egyptian cotton. Minimizing deleterious effects through the application of proper management practices, such as, adequate irrigation regime, and utilization of specific plant growth regulators could limit the negative effects of some climatic factors [4-6].

\section{References}

1. Sawan ZM (2013) Studying the relationship between climatic factors and cotton production by different applied methods. Journal of Stress Physiology \& Biochemistry 9: 251-278.
2. Sawan ZM (2014) Climatic factors: evaporation, sunshine, relative humidity, soil and air temperature and cotton production. Annual Research \& Review in Biology 4: 2835-2855.

3. Sawan ZM (2014) Nature relation between climatic variables and cotton production. Journal of Stress Physiology \& Biochemistry 9: 251278 .

4. Sawan ZM (2015) Statistical methods to evaluate the relationship between climatic factors during the development periods of flowering and boll formation and cotton production. International Journal of Environmental Science \& Natural Resources 1: 1-8.

5. Sawan ZM (2016) Climatic factors; cotton production: studying its relationships by different applied statistical methods. Journal of Statistics and Mathematical 2: 109-120.

6. Sawan ZM (2016) Different applied mathematics and statistics methods to evaluate the response of cotton production to climatic variables. Elixir International Journal, Elixir Statistics 92: 3934839364.

\section{Your next submission with Juniper Publishers} will reach you the below assets

- Quality Editorial service

- Swift Peer Review

- Reprints availability

- E-prints Service

- Manuscript Podcast for convenient understanding

- Global attainment for your research

- Manuscript accessibility in different formats ( Pdf, E-pub, Full Text, Audio)

- Unceasing customer service

Track the below URL for one-step submission https://juniperpublishers.com/online-submission.php 